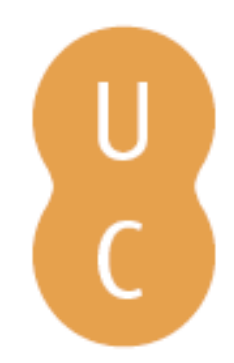

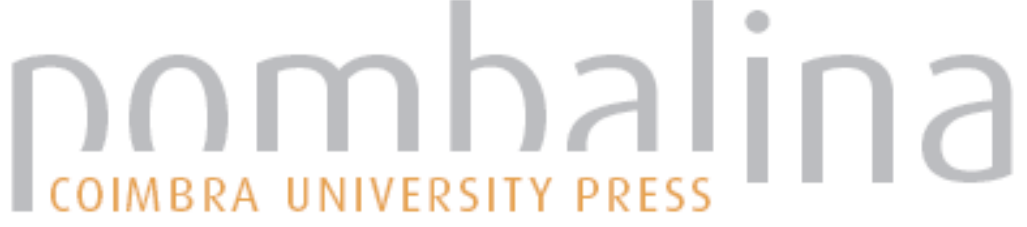

\section{Estudo de taludes instáveis na estrada LubangoHumpata, SW de Angola}

\author{
Autor(es): $\quad$ Andrade, P. S.; Prego, G.; QuintaFerreira, M.
}

Publicado por: Imprensa da Universidade de Coimbra

URL

persistente: URI:http://hdl.handle.net/10316.2/31491

DOI: $\quad$ DOI:http://dx.doi.org/10.14195/978-989-26-0531-9_45

Accessed : $\quad$ 26-Apr-2023 06:21:49

A navegação consulta e descarregamento dos títulos inseridos nas Bibliotecas Digitais UC Digitalis, UC Pombalina e UC Impactum, pressupõem a aceitação plena e sem reservas dos Termos e Condições de Uso destas Bibliotecas Digitais, disponíveis em https://digitalis.uc.pt/pt-pt/termos.

Conforme exposto nos referidos Termos e Condições de Uso, o descarregamento de títulos de acesso restrito requer uma licença válida de autorização devendo o utilizador aceder ao(s) documento(s) a partir de um endereço de IP da instituição detentora da supramencionada licença.

Ao utilizador é apenas permitido o descarregamento para uso pessoal, pelo que o emprego do(s) título(s) descarregado(s) para outro fim, designadamente comercial, carece de autorização do respetivo autor ou editor da obra.

Na medida em que todas as obras da UC Digitalis se encontram protegidas pelo Código do Direito de Autor e Direitos Conexos e demais legislação aplicável, toda a cópia, parcial ou total, deste documento, nos casos em que é legalmente admitida, deverá conter ou fazer-se acompanhar por este aviso. 



\title{
ESTUDO DE TALUDES INSTÁVEIS NA ESTRADA LUBANGO-HUMPATA, SW DE ANGOLA
}

\author{
STUDY OF UNSTABLE SLOPES \\ IN THE LUBANGO-HUMPATA ROADWAY, SW ANGOLA
}

P. S. Andrade'; G. Prego ${ }^{2} \&$ M. Quinta-Ferreira ${ }^{1}$

\begin{abstract}
Resumo - No presente trabalho caracterizam-se as situaçóes de instabilidade de dois taludes rodoviários localizados na Estrada Nacional 280, que se situam próximos da cidade de Lubango, SW de Angola. Os taludes são constituídos essencialmente por quartzo-arenitos de tonalidades esbranquiçadas, amareladas a acinzentadas e são sobrepostos por depósitos de cobertura. Nos taludes têm ocorrido situaçóes de instabilidade tais como quedas de blocos, deslizamentos planares e em cunha. A caracterização dos taludes foi efectuada recorrendo à cartografia geológica e estrutural, à realização de ensaios in situ e à utilização das classificaçóes Rock Mass Rating (RMR), Slope Mass Rating (SMR) e Rockfall Hazard Rating System. Avaliaram-se as ocorrências de instabilidade e apresentam-se possíveis medidas de redução e de mitigação das situaçôes de instabilidade.
\end{abstract}

Palavras-chave - Estabilidade de taludes; RMR; SMR; Rockfall Hazard Rating System; Lubango

Abstract - The stability problems of two road cut slopes located on National road 280, near Lubango, SW Angola, are characterized. The slopes are mainly composed by quartz sandstones with whitish, yellowish and greyish colors and are overlaid by debris deposits. The slopes presented stability movements such as rockfalls, planar and wedge failures. A geological and structural survey and in situ tests were carried out. The Rock Mass Rating (RMR), the Slope Mass Rating (SMR) classifications as well as the Rockfall Hazard Rating System

\footnotetext{
${ }^{1}$ Departamento de Ciências da Terra e Centro de Geociências da Universidade de Coimbra, Largo Marquês de Pombal, 3000-272 Coimbra, Portugal; pandrade@dct.uc.pt; mqf@dct.uc.pt

${ }^{2}$ Mestre pela Universidade de Coimbra e pela Universidade Privada de Angola; guidoprego@yahoo.com.br
} 
were used. The slope movements were analyzed and some slope prevention and stabilization procedures are defined.

\section{1 - Introduçáo}

No trabalho pretende-se identificar os problemas de instabilidade de dois taludes da Estrada Nacional 280, que é a via rodoviária principal entre Lubango e Humpata. Esta estrada constitui a principal ligação entre as províncias da Huíla e do Namibe, sendo através dela que se efectua o intercâmbio de vários produtos comerciais e industriais.

$\mathrm{Na}$ zona estudada registam-se situaçóes de instabilidade dos taludes, em particular a queda de blocos rochosos, desde a construção da estrada. No troço entre Lubango e Humpata, nunca se efectuaram medidas de protecção ou de estabilização dos taludes, de modo a evitar ou reduzir os fenómenos de instabilidade.

A área de estudo compreende dois taludes, situando-se na província da Huíla, no município do Lubango, na Estrada Nacional 280, entre Lubango e o município da Humpata. O Talude 1 compreende dois troços (Fig. 1).

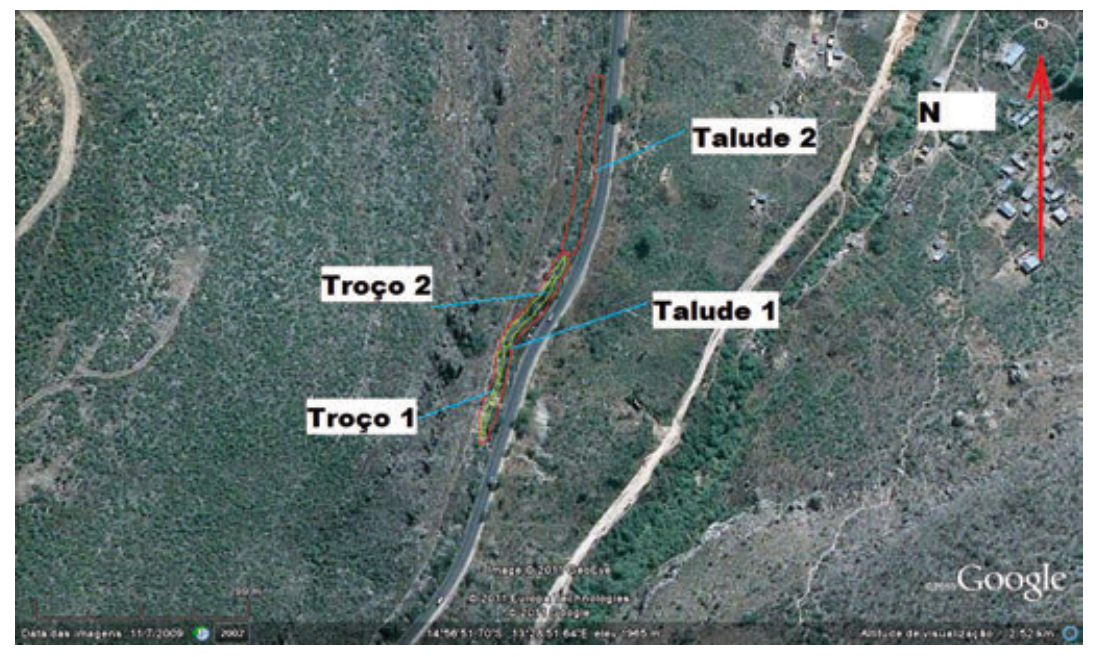

Fig. 1 - Localização dos taludes estudados (Google Earth, 2010).

\section{2 - Enquadramento geográfico e geológico}

A área encontra-se a uma cota compreendida entre 1970 e 1980 metros. Na parte inferior da vertente regista-se a presença de uma área habitacional denominada bairro "A Luta Continua" onde habitam entre 250 a 300 pessoas. Nos últimos anos tem-se registado um incremento na construção em algumas das vertentes adjacentes à via de comunicação, em parte devido às suas características paisagísticas. $\mathrm{O}$ clima da província 
da Huíla apresenta características variadas, sendo geralmente considerado, como quente ou tropical (temperatura média anual superior a $20^{\circ} \mathrm{C}$ ). Nas áreas de cota mais elevada, como é o caso da área urbana de Lubango, pode ser considerado como temperado ou como temperado quente. O período de maior pluviosidade ocorre nos meses de temperatura mais elevada, de modo geral entre Outubro a Abril, os meses de Junho e Julho tendem a ser muito secos (SINFIC, 2007).

As rochas graníticas são aflorantes numa parte muito considerável da província da Huíla e são parte integrante das formaçôes eruptivas do Maciço Antigo. No caso dos granitos presentes na área de Lubango estes têm uma idade superior a 2250 milhóes de anos, têm grão fino a grosseiro e são definidos como granitos porfiróides a gnáissicos, podendo por vezes ser considerados como granodioritos.

As formaçóes do Grupo Chela que correspondem a um grupo de rochas sedimentares e vulcanoclásticas, são sobrejacentes ao granito existente na cidade do Lubango, e têm idade Proterozóica, entre 1100 a 1400 milhóes de anos (CARVALHO \& ALVES, 1993), podendo atingir espessuras superiores a $500 \mathrm{~m}$ (CORREIA, 1976).

Os taludes analisados enquadram-se no Grupo Chela, sendo constituídos por quartzo-arenitos com tonalidades esbranquiçadas a amareladas e acastanhadas, por vezes róseas, estas últimas relacionadas com fenómenos de oxidação. Os quartzo-arenitos possuem textura granular e grão médio a fino, por vezes pode observar-se estratificação entrecruzada. A sua resistência tende a ser elevada, o que está relacionado com a sua composição quartzosa.

Na parte superior dos taludes verifica-se a presença de depósitos de cobertura, resultantes da atuação de processos erosivos e de movimentos de instabilidade de vertentes nos afloramentos localizados a cotas superiores aos taludes estudados. A espessura dos depósitos de cobertura é variável, entre 1,0 a 1,5 m, no primeiro talude, e de 1,0 a 2,5 $\mathrm{m}$ no segundo talude. Os depósitos de cobertura são heterométricos e por vezes pouco consolidados. Os componentes mais grosseiros podem apresentar uma dimensão de 0,30 $\mathrm{m}^{3}$. A composiçáo dos depósitos de cobertura apresenta-se variável, mas verifica-se um predomínio de quartzitos, quartzo-arenitos e arenitos, observando-se igualmente material arenoso. A permeabilidade dos depósitos é superior à dos quartzo-arenitos, nos quais a circulação da água se efectua pelas superfícies das descontinuidades.

\section{3 - Metodologia}

No estudo seleccionaram-se taludes rodoviários em que se verificam situaçóes de instabilidade. A caracterização geológica foi efectuada através da observação macroscópica e da utilização do martelo de geólogo, definindo-se a dureza das formaçóes rochosas através da utilização do martelo de Schmidt.

Para a utilização das classificações geomecânicas procedeu-se a um levantamento geológico e estrutural que permitiu definir as famílias de descontinuidades e as suas características.

Determinaram-se os valores do espaçamento, material de preenchimento, estado de alteração, persistência, abertura e rugosidade das superfícies das descontinuidades, bem como da percolaçáo e dos parâmetros geométricos dos taludes, das dimensóes da plataforma da via rodoviária e da respectiva vala. Procedeu-se à captação de imagens fotográficas da totalidade da extensão dos taludes. 
Nos locais selecionados procedeu-se à elaboração da cartografia geológica e estrutural e à definição das situaçôes de instabilidade. No estudo dos taludes aplicaram-se as classificações geomecânicas “Rock Mass Rating” (RMR) de BIENIAWSKI (1979 e 1989), o "Slope Mass Rating” (SMR) de ROMANA (1996). A classificação RMR permite uma utilização para diferentes tipos de obras de engenharia, enquanto a classificação SMR de Romana está direcionada para o estudo de taludes. As classificaçôes RMR e SMR são aplicadas em maciços rochosos e requerem a definição de um zonamento prévio dos maciços.

Foi também aplicada a classificação "Rockfall Hazard Rating System" (RHRS) (PIERSON et al., 1990).

\section{1 - Classificação SMR}

A classificação SMR corresponde a um método de avaliação das situaçôes de instabilidade dos taludes rochosos. O SMR é definido a partir da classificação RMR, adicionando-se ao valor do RMR a multiplicação de um conjunto de factores que estão associados ao tipo de movimento de instabilidade, planar ou basculamento (toppling), à orientação das descontinuidades e dos taludes (Equação 1). Deve mencionar-se igualmente a presença do factor F4, que está relacionado com o método empregue no processo de escavação ou desmonte do talude. Os valores do SMR e a avaliação geral das condiçóes da estabilidade permitem definir medidas de estabilização para os taludes.

$$
\mathrm{SMR}=\mathrm{RMR}+(\mathrm{F} 1 \times \mathrm{F} 2 \times \mathrm{F} 3)+\mathrm{F} 4
$$

F1 é obtido através da diferença em valor absoluto entre as direcçôes das descontinuidades e do talude. F1 apresenta valores entre 0,15 e 1,0.

F2 é definido a partir do pendor das descontinuidades e tem, para as roturas do tipo planar, valores compreendidos entre 0,15 e 1,0, sendo este último valor para pendores superiores a $45^{\circ}$. Para as roturas por basculamento considera-se que F2 apresenta valores constantes de 1,0 .

F3 está relacionado com a diferença entre os pendores das descontinuidades e das faces dos taludes. Os valores de F3 variam entre 0 e -60 para a rotura planar e 0 e -25 para a rotura por basculamento.

F4 assume o valor de +15 para taludes naturais ou vertentes, +8 para os desmontes efectuados com explosivos do tipo "smooth blasting", 0 para a escavação mecânica ou por explosivos e de -8 para desmontes de má qualidade executados com explosivos.

\section{2 - Classificação Rockfall Hazard Rating System (RHRS)}

Na classificação "Rockfall Hazard Rating System" (RHRS), que pode ser designada como Sistema de Avaliação do Perigo de Queda de Blocos Rochosos, procede-se à definição das condiçôes de estabilidade relativas a cada talude com vista à definição do risco relacionado com as situaçóes de instabilidade de material rochoso para a circulação automóvel.

Os diferentes parâmetros constituintes da classificaçáo RHRS são: altura do talude, eficácia da vala, risco médio para veículos, distância de visibilidade de decisão, largura 
da plataforma da via, natureza geológica (Caso 1 - Condição estrutural e atrito da rocha; Caso 2 - Condição estrutural e diferença em taxas de erosão), tamanho do bloco ou quantidade de blocos caídos por evento e presença de água no talude. Os vários parâmetros são classificados em valores ponderais, numa escala de 3, 9, 27 e 81 pontos (PIERSON et al., 1990).

\section{4 - Aplicação da metodologia}

\section{1 - Características dos taludes}

O talude 1 apresenta 13,5 metros de altura média e 100 metros de comprimento, cada troço tem cerca de 50 metros de extensão. O talude 2 tem uma altura média de 8 metros e um comprimento de 100 metros.

O material rochoso no $1^{\mathrm{o}}$ troço do Talude 1 apresenta um menor grau de alteração, mas também se registaram situaçóes de instabilidade. No $2^{\circ}$ troço do Talude 1 , o material rochoso encontra-se mais fracturado e os valores da abertura das descontinuidades são mais elevados.

Nos últimos anos têm-se registado situaçôes de instabilidade, em particular no Talude 1, registando-se a presença de blocos tombados na base desse talude. No decorrer de Março de 2011 observou-se a queda de blocos rochosos na via rodoviária. Estas ocorrências de instabilidade estão relacionadas com as precipitaçóes elevadas que se verificaram no referido mês.

Para cada troço do talude 1 efectuou-se a determinação da resistência à compressão uniaxial do material rochoso ( $\sigma$ ) através da utilização do martelo de Schmidt, do tipo L. No primeiro troço do talude 1, para o material de menor resistência, definiu-se o valor de $\sigma$ de aproximadamente de $34 \mathrm{MPa}$, pelo que o valor ponderal do parâmetro relativo a $\sigma$ na classificação RMR assume o valor de 4 .

$\mathrm{Na}$ zona de resistência mais elevada, do primeiro troço, do Talude 1 , o valor de $\sigma$ é de $120 \mathrm{MPa}$ e na classificação RMR o valor ponderal corresponde a 12.

Para o segundo troço do Talude 1 determinou-se para a zona de menor resistência um valor médio de $\sigma$ de cerca de $26 \mathrm{MPa}$, pelo que o seu peso na classificação RMR foi definido como igual a 4. Para a zona de maior resistência, do segundo troço, do Talude 2 , obteve-se um valor de $\sigma$ de $110 \mathrm{MPa}$, o que permitiu definir um valor ponderal de 12 , de acordo com a classificação RMR.

No decorrer do levantamento de campo não se verificou percolação de água nas superfícies de descontinuidade, mas a abertura das descontinuidades e o aspecto oxidado das suas superfícies indicia a existência de percolação de água nos períodos de maior precipitação.

\section{2 - Utilização das classificaçốes RMR e SMR}

O primeiro troço do talude 1 (Fig. 2) possui três famílias de descontinuidades que foram designadas como $\mathrm{H}, \mathrm{S}$ e $\mathrm{O}$, enquanto o segundo troço tem 4 famílias que foram denominadas como $\mathrm{H}, \mathrm{S}, \mathrm{O}$ e $\mathrm{A}$. As descontinuidades da família $\mathrm{H}$ correspondem à estratificação. 

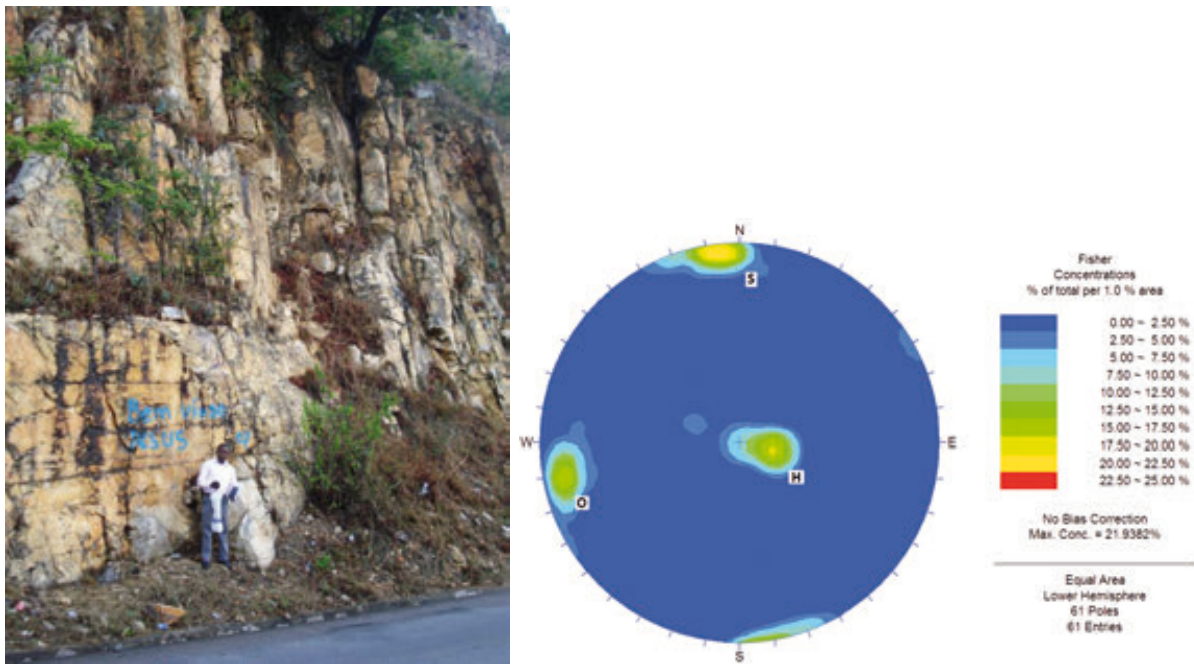

Fig. 2 - Vista parcial do talude e representação da projeção estereográfica dos polos das descontinuidades no primeiro troço do talude 1.

As classificaçóes RMR e SMR foram aplicadas nos dois troços do Talude 1, os resultados são apresentados nas Tabelas 1 a 4 .

Os valores do RMR apresentados na Tabela 1 para o maciço rochoso mais resistente do primeiro troço revelaram-se próximos, com uma diferença máxima de 5 pontos. O maciço rochoso foi classificado como de boa qualidade. Para a parte de menor resistência do primeiro troço definiu-se o maciço rochoso como de qualidade razoável a boa (Tabela 2).

Tabela 1 - Valores das classificaçôes RMR e SMR para as diferentes famílias de descontinuidades presentes na zona de resistência mais elevada do $1^{\circ}$ troço do talude 1

\begin{tabular}{lccc}
\hline $1^{\circ}$ Troço & H & S & 0 \\
\hline RMR & 71 & 72 & 67 \\
SMR (Rotura Planar) & 70 & 71 & 49 \\
SMR (Rotura por Toppling) & 71 & 68 & 63 \\
\hline
\end{tabular}

Tabela 2 - Valores das classificaçôes RMR e SMR para as diferentes famílias de descontinuidades presentes na zona de resistência mais reduzida do $1^{\circ}$ troço do talude 1.

\begin{tabular}{lccc}
\hline $1^{\circ}$ Troço & H & S & 0 \\
\hline RMR & 61 & 62 & 57 \\
SMR (Rotura Planar) & 60 & 61 & 39 \\
SMR (Rotura por Toppling) & 61 & 58 & 53 \\
\hline
\end{tabular}

De acordo com os valores apresentados na Tabela 3 verificou-se que o maciço rochoso de maior resistência do segundo troço pode ser classificado como de boa qualidade. Os valores do RMR para o maciço rochoso de menor resistência do segundo troço permitiram definir este último como de qualidade razoável se exceptuarmos os resultados relacionados com a família $\mathrm{H}$ (Tabela 4). 
Tabela 3 - Valores das classificações RMR e SMR para as diferentes famílias de descontinuidades presentes na zona de resistência mais elevada do $2^{\circ}$ troço do talude 1 .

\begin{tabular}{lcccc}
\hline 10 Troço & H & S & 0 & A \\
\hline RMR & 71 & 70 & 65 & 67 \\
SMR (Rotura Planar) & 70 & 66 & 58 & 43 \\
SMR (Rotura por Toppling) & 71 & 66 & 61 & 63 \\
\hline
\end{tabular}

Tabela 4 - Valores das classificaçôes RMR e SMR para as diferentes famílias de descontinuidades presentes na zona de resistência mais reduzida do $2^{\circ}$ troço do talude 1 .

\begin{tabular}{lcccc}
\hline $1^{\text {o }}$ Troço & H & S & 0 & A \\
\hline RMR & 61 & 60 & 55 & 57 \\
SMR (Rotura Planar) & 60 & 56 & 48 & 33 \\
SMR (Rotura por Toppling) & 61 & 56 & 51 & 53 \\
\hline
\end{tabular}

Na determinação do SMR efectuou-se a obtenção prévia do RMR para cada família de descontinuidades presentes na respectiva secção do maciço rochoso. O valor de F4 foi considerado igual a zero. Os resultados do SMR para o primeiro e segundo troços do talude 1 são apresentados nas Tabelas 1 a 4 .

Para os valores do SMR e de acordo com os critérios de ROMANA (1996) consideraram-se os valores mais baixos obtidos, pelo que para o primeiro troço do talude 1 é igual a 39, verificando-se que este valor está relacionado com as descontinuidades da família $\mathrm{O}$ e a roturas do tipo planar (Tabela 2). O valor de SMR de 39 permite classificar o $1^{\circ}$ troço do talude 1 como instável, podendo-se verificar roturas planares ou em cunha de grandes dimensóes. Para o $2^{\circ}$ troço do talude 1 definiu-se que o valor mais baixo do SMR corresponde a 33, o que o permite enquadrar como instável de acordo com a classificação SMR de ROMANA (1996). É de salientar que o valor de 33 é inferior ao encontrado para o $1^{\circ}$ troço do talude 1 , o que está de acordo com as observaçóes in situ, em que se registaram mais situaçóes de instabilidade no $2^{\circ}$ troço do que no $1^{\circ}$ troço do talude 1 .

Os valores da classificação RHRS para o primeiro e segundo troços do talude 1 foram, respectivamente, 314 e 343 , enquanto para o talude 2 se obtiveram, considerando respetivamente as condiçóes geológicas do Caso 1 e do Caso 2, os valores de 244 e 235.

De acordo com o Sistema de Transportes do Estado de Oregon (PIERSON et al., 1990) e HOEK (2007), os taludes cujo somatório dos valores dos parâmetros da classificação RHRS são menores que 300 devem ser considerados como de prioridade baixa, enquanto os taludes com RHRS superior a 500 devem ser sujeitos a acçóes de estabilização urgente.

Para os troços do talude 1 devem ser tomadas medidas de mitigação e de estabilização, dado que o somatório dos parâmetros da RHRS é superior a 300, para o talude 2 esses tipos de acçôes poderão ser igualmente adoptados mas não de uma forma prioritária, dado que os valores do somatório dos parâmetros da RHRS são menores do que 300 . Os valores do SMR para o $2^{\circ}$ troço do talude 1 definiram a possibilidade de processos de instabilidade mais acentuados, os resultados da classificação RHRS, para esse mesmo troço, permitiram definir uma situação em que a adopção de medidas de estabilização deveria ser efectuada mais rapidamente do que no $1^{\circ}$ troço do talude 1 e no talude 2 . 


\section{3 - Medidas de estabilização}

Podem adoptar-se medidas de estabilidade nos taludes a partir dos resultados das classificaçôes SMR e RHRS, bem como da caracterização efetuada in situ. Numa fase inicial de estabilizaçấo dos taludes deve efetuar-se o saneamento de blocos rochosos de volume significativo e que se apresentem com sinais de instabilidade. Devem ser instalados sinais de trânsito, de modo a avisar os condutores da eventualidade da queda de blocos rochosos.

Tendo em atenção os valores do SMR e obtidos pela classificação RHRS, recomenda-se a utilização de redes de protecção metálicas e de pregagens para o primeiro troço do talude 1. Em algumas zonas do maciço rochoso, mais fracturadas e alteradas deste troço, poderá utilizar-se betão projectado. Para o $2^{\circ}$ troço do talude 1 propóe-se a colocaçáo de redes metálicas e o reforço do talude através de pregagens que devem ser sistemáticas e mais profundas na parte do troço mais sujeita a situaçóes de instabilidade, em particular onde se podem verificar quedas de blocos de maior dimensão e que estão relacionadas com as descontinuidades da família A, o betão projectado pode ser empregue nas zonas de fracturação de menor espaçamento e com um grau de alteração mais elevado.

O talude 2 deve ser monitorizado de modo a verificar a evolução das situaçóes de instabilidade, podendo adoptar-se medidas de estabilização se os blocos rochosos na sua trajetória atingirem a plataforma da via rodoviária. Os eventuais problemas de instabilidade originados pelos depósitos de cobertura podem ser minimizados através de açóes de saneamento no cimo dos taludes e pela diminuição do pendor dos referidos depósitos.

\section{5 - Conclusóes}

No presente estudo caracterizam-se algumas das situaçóes de instabilidade na estrada que liga Lubango e Humpata. Os taludes estudados apresentam-se constituídos principalmente por quartzo-arenitos ou quartzitos, verificando-se a presença de depósitos de cobertura que são originados por processos erosivos.

Registaram-se ocorrências de situaçôes de instabilidade nos taludes 1 e 2 , designadamente a queda de blocos rochosos, podendo verificar-se igualmente deslizamentos planares e em cunha. As quedas de blocos verificam-se com uma maior frequência no talude 1 do que no talude 2 .

As situações de instabilidade são originadas pela orientação desfavorável das descontinuidades e pela presença da água, existindo queda de blocos rochosos, em particular nos períodos de maior precipitação.

Os valores do RMR do talude 1 (primeiro e segundo troços) revelaram que o maciço rochoso de maior resistência pode ser classificado de boa qualidade. O maciço rochoso de menor resistência, do $1^{\circ}$ troço do talude 1 , tem qualidade intermédia a boa, enquanto o do $2^{\circ}$ troço do talude 1 tem predominantemente uma qualidade razoável.

Os valores mais baixos que foram obtidos através da classificação SMR permitiram definir os dois troços do talude 1 como instáveis.

Na utilização da classificação RHRS, no primeiro e no segundo troço do talude 1 obtiveram-se, respectivamente, valores de 314 e 343. Para o talude 2 consoante se considerou o maciço rochoso ou os depósitos de cobertura determinaram-se valores de 244 
ou 235. Os dois troços do talude 1, de acordo com os valores da classificação RHRS são considerados como susceptíveis de intervençáo, mas náo constituem situaçóes em que a estabilização deve ser realizada de forma imediata.

No primeiro troço do talude 1 as medidas de estabilização são a utilização de redes metálicas associadas ao emprego de pregagens, podendo utilizar-se, por vezes, betáo projectado. No segundo troço do talude 1 podem empregar-se métodos de estabilização idênticos aos do primeiro troço devendo ter-se o cuidado de utilizar pregagens de maior profundidade nos blocos potencialmente instáveis e que apresentam maiores dimensóes.

Para o talude 2 é recomendada a realização de observaçôes periódicas de modo a monitorizar a possível ocorrência de instabilidades.

Agradecimentos - Este trabalho foi financiado pelo Estado Português através da FCT - Fundação para a Ciência e a Tecnologia no âmbito do projecto PEst-OE/CTE/ UI0073/2011 do Centro de Geociências.

\section{Referências Bibliográficas}

BIENIAWSKI, Z.T. (1979) - The Geomechanics Classification in rock engineering applications. Proc. of the Fourth Congress International on Rock Mechanics, Montreux, Canada. Balkema, Boston, p. 51-58.

BIENIAWSKI, Z.T. (1989) - Engineering Rock Mass classifications. Wiley, New York.

CARVAlHO, H. \& ALVES, P. (1993) - The Precambrian of SW Angola and NW Namibia. General Remarks. Correlation Analysis. Economic Geology. Comunicaçôes do Instituto de Investigação Científica e Tropical, Série de Ciências da Terra, 4.

CORREIA, H. (1976) - O Grupo Chela e a formação Leba como novas unidades litoestratigráficas resultantes da redefinição da "Formação da Chela" na regiāo do planalto da Humpata (Sudoeste de Angola). Boletim da sociedade Geológica de Portugal, vol. XX (I-II), p. 65-130.

HOEK (2007) - Practical rock engineering. http://www.rocscience.com/hoek. (Consultado em 2011.12.15).

PIERSON, L.A.; DAVIS, S.A. \& VAN VICKLE, R. (1990) - Rockfall Hazard Rating System Implementation Manual. Federal Highway Administration (FHWA). US Department of Transportation.

ROMANA, M. (1996) - The SMR geomechanical classification for slopes: A critical ten-years review. Proceedings of the Eighth International Conference and Field Trip on Landslides, Granada, Spain. Balkema (Ed.), Rotterdam, pp. 255-267.

SINFIC (2007) - Plano de desenvolvimento da província da Huíla, Caracterização Ambiental. Sistemas de Informação Industriais e Consultoria (SINFIC). 